\title{
Comparative Morphological Studies of the Stifle Menisci in Donkeys, Goats and Dogs
}

\author{
Mohamed M.A. Abumandour ${ }^{1} \quad$ Naglaa Fathi Bassuoni ${ }^{1} \quad$ Samir El-Gendy ${ }^{1}$ Ashraf Karkoura ${ }^{1}$ \\ Raafat El-Bakary ${ }^{1}$ \\ ${ }^{1}$ Department of Anatomy and Embryology, Faculty of Veterinary \\ Medicine at Alexandria University, Behera, Egypt \\ Address for correspondence Mohamed M. A. Abumandour, Assistant \\ Professor of Anatomy and Embryology, Faculty of Veterinary Medicine \\ at Alexandria University, Rashid, Edfina, Behera, Egypt, \\ J Morphol Sci 2019;36:72-84. \\ Postal Box: 22785 (e-mail: m.abumandour@yahoo.com).
}

\begin{abstract}
Keywords

- stifle joint

- meniscal ligaments

- computed tomography

- anatomical sections

The present work aims to provide more anatomical information on the stifle joint of the investigated species using computed tomography with gross anatomical cross-sections. The current work analyzed the stifle joint of the pelvic limbs of 12 adult donkeys, goats and dogs of both genders. The medial condyle of the femur was larger than the lateral one in the donkey, while it was smaller and lower than the lateral one in the goat and in the dog. The unsuitable femoral and tibial condyles were adapted by the presence of menisci. In the donkey, the medial meniscus was crescentic in shape, but it was semicircular in the goat, while in the dog, the medial and lateral menisci were $\mathrm{C}-$ shaped. In the donkey, the medial meniscus was larger than the lateral one, but in the goat and in the dog, the lateral meniscus was the largest, and more concave and thicker. The lateral meniscus was semicircular in the donkey, but it was shaped like an elongated kidney in the goat. In the goat and in the dog, the central border of two menisci was thin, concave and notched centrally. The meniscal ligaments included cranial and caudal ligaments of the medial and lateral menisci, and meniscofemoral ligament of the lateral meniscus. In the dog, the cranial ligament of the medial meniscus was absent, and the medial meniscus had no bony attachment to the tibia but it attached to the transverse intermeniscal ligament, which connected the cranial horn of the medial meniscus with the cranial ligament of the lateral meniscus. The meniscofemoral ligament connected the caudal pole of the lateral meniscus with the intercondyloid fossa of the femur.
\end{abstract}

\section{Introduction}

Anatomically, the stifle meniscus is described as a crescenticshaped or semilunar fibrocartilaginous plate wedged between the femoral and tibial condyles. Its role is to provide structural integrity to the stifle joint during joint tension and torsion due to unsuitable articulation between the femoral and tibial condyles as well as to provide joint stabilization, shock absorption and protection of the articular surface. ${ }^{1-6}$

It is of vital importance to understand the morphological appearance of the stifle meniscus in animals because they are used as medical models to measure the degree of success of treatment options for meniscal injury ${ }^{7}$ in humans and to

received

November 5, 2018

accepted

February 15, 2019
DOI https://doi.org/

10.1055/s-0039-1685487. ISSN 2177-0298. know more about surgery of the stifle joint in animals. ${ }^{8,9} \mathrm{~A}$ few examples of meniscal surgery models most frequently used are small animals (dog and pig), small ruminants (goat, sheep) and large ruminants (cow)., $, 7,10-13$

The stifle joint is usually exposed to many problems that may require surgical treatment, such as patellar luxation, gonitis (stifle arthritis), synovitis, fracture, meniscal tearing and cruciate ligament sprain in the bovine. ${ }^{14}$ Most commonly, sheep, goats, pigs, dogs, and rabbits are used as models of the human knee to test implants or to discover determinants of disease progression. ${ }^{15-18}$

Computed tomography (CT) is an efficient imaging modality that provides a cross-sectional image with superior soft

Copyright @ 2019 by Thieme Revinter

Publicações Ltda, Rio de Janeiro, Brazil

License terms

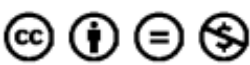


tissue differentiation and no superimposition of the overlying structures, which can be used for better diagnosis of foot and foot pad abnormalities. ${ }^{19,20}$ The CT is considered an important diagnostic tool in the human diagnosis, but due to its high cost, it is not used as often in veterinary diagnosis. ${ }^{21}$ Moreover, the CT technique is useful for evaluation of the osseous structure, and it also gives three-dimensional CT images to provide a better view of the ligaments during surgery. ${ }^{22}$

The purpose of the present study was to provide a detailed anatomic reference of CT images interpreted with gross anatomical cross-sections of the normal stifle menisci of donkeys, goats and dogs for anatomists, surgeons and veterinary students.

\section{Material and Methods}

\section{Samples}

Six healthy adult animals of both genders, from each species, were used in the current study. The used animals were free of any anatomical abnormalities and any stifle joint affection. They were collected from the farms near the Kafr El-Sheik government. Joints from the right and left limbs were used. The current study was performed according to the guidelines for the care and use of laboratory animals and the Animal Welfare and Ethics Committee of the Faculty of Veterinary Medicine at Alexandria University, following the Egyptian's laws. The anatomical terms follow the Nomina Anatomica Veterinaria (NAV). ${ }^{23}$

\section{Gross Morphology Examination}

Four pelvic limbs from each animal species were used for studying the articular surfaces of the femorotibial joint. The animals were bled after being anesthetized; then, the three pelvic limbs were separated and buried in soil until complete decomposition of the tissues. After that, the bones of the two joints were collected, washed thoroughly using water and soap, and then bleached with hydrogen peroxide for 1 day and left to dry. The bones were then photographed after studying the characteristics of the articular surfaces of the stifle joint. Finally, the characteristic features of the bones were photographed with a Canon IXY 325 digital camera (Canon, Tokyo, Japan) after studying the characteristics of the articular surfaces of the stifle joint.

Four pelvic limbs from each species were used for studying the stifle meniscus ligaments. The animals were bled after being anesthetized, and, then, they underwent routine preservative technique ( $10 \%$ formalin mixed with $4 \%$ glycerin and $1 \%$ phenol) for 10 to 15 days until complete fixation. Finally, the two pelvic limbs were separated and the stifle meniscus ligaments were dissected.

\section{Computed Tomography}

Four pelvic limbs from each animal species were obtained, and the stifle joint was severed and used for studying it by means of a CT. The animas were anesthetized and then bled, and the joints were separated and transferred to the CT center within 24 hours, where they were analyzed using a Toshiba ASTEION SUPER-4 multi slice 4CT scanner(Toshiba Corp., Minato, Tokyo,
Japan) at $120 \mathrm{KV}$ and $150 \mathrm{mAs}$. The distance between the slices taken was $0.5 \mathrm{~cm}$. Three-dimensional images were also taken by the CT scanner for reconstruction of the stifle joint. Bone and soft tissue window images were taken.

\section{Statistical Analysis}

The IBM SPSS Statistics for Windows, Version 21.0 software (IBM Corp., Armonk, NY, USA) ${ }^{24}$ was used for making a correlation between the articular surfaces of the femorotibial joint and the body weight of the donkey, the goat and the dog.

\section{Results}

\section{Articular Surface}

Anatomically, the stifle joint consists of two main joints: the femorotibial and femoropatellar joints. The femorotibial articulation (articulatio femorotibialis) is formed between the condyles of the femur, the condyles of the tibia and the medial and lateral menisci.

\section{Medial and Lateral Condyles of the Femur (Condylus Medialis and Lateralis)}

The head of the femur has two condyles: medial and lateral. The medial condyle was larger than the lateral one in the donkey ( - Fig. 1A/4), while it was smaller and lower than the lateral one in the goat (-Fig. 2A/4) and in the $\operatorname{dog}(-$ Fig. 3A/ 4). Furthermore, the correlation between the length and weight of the medial and lateral condyles of the femur was demonstrated in - Fig. 4.

In the three examined animals, the medial condyle of the femur was semispherical in shape and oblique in direction; on the other hand, the lateral condyle was sagittal in direction (-Fig. 1A; 2A and 3A/5). In the dog, the articular surfaces of the two condyles were continuous proximocaudally with small articular facet for sesamoid bones (-Fig. 7C and 12B) ms and Is), which present in the tendons of the medial and lateral head of the gastrocnemius muscle.

In the three species, we observed a fossa located between the lateral ridge of the trochlea of the femur and the lateral condyle. This is called the extensor fossa (-Fig. 1A; 2A and $\mathbf{3 A} / 9$ ), which marks the origin of the long digital extensor muscle and peroneus tertius in the donkey and goat but the origin of the long digital extensor muscle only in the dog. The intercondyloid fossa (-Fig. 1A, 2A and 3A/8) was deep and sagittal in direction. In the dog, this fossa was deeper caudally than cranially. The length and width were calculated as means and recorded in - Table 1.

\section{Medial and Lateral Condyles of the Tibia (Condylus Medialis and Lateralis)}

These condyles were not adapted with the condyles of the femur and there was only a small contact area with them. This adaptation was compensated by the presence of the menisci. In the donkey ( $\mathbf{F i g} \cdot \mathbf{1 A} / \mathbf{1 0}$ ) and in the goat ( $\mathbf{F i g . ~ 2 A / 1 0}$ ), the articular surface of the medial condyle of the tibia was triangular in outlines, while the lateral condyle was quadrilateral, but in the dog, the medial condyle (-Fig. 3B/10) was oval in shape, and the lateral condyle (-Fig. $\mathbf{3 B} / \mathbf{1 1}$ ) was nearly 


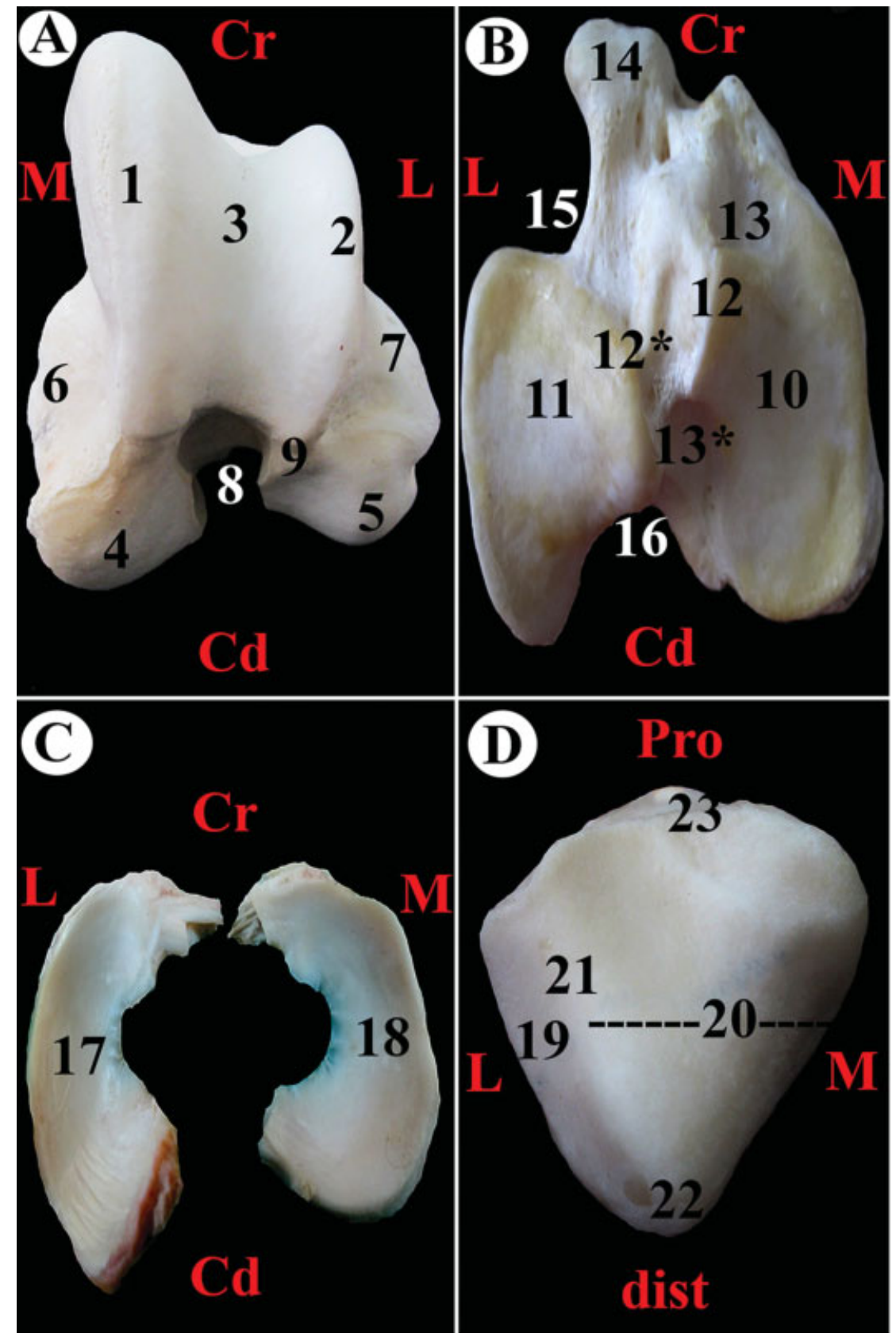

Fig. 1 Gross morphological views of the articular surfaces of the left stifle joint of the donkey: (View A) clarifies the distal extremity of the femur, (View B) clarifies the proximal extremity of the tibia, (View C) clarifies the menisci, (View D) clarifies the articular surface of the patella. 1- Medial ridge of the trochlea of the femur. 2-Lateral ridge of the trochlea of the femur. 3-Trochlear groove. 4- Medial condyle. 5- Lateral condyle. 6- Medial epicondyle. 7- Lateral epicondyle. 8- Intercondyloid fossa. 9- Extensor fossa. 10- Medial condyle. 11- Lateral condyle. 12- Medial part of the intercondyloid eminence. 12*- lateral part of the intercondyloid eminence. 13- Cranial part of intercondyloid fossa. 13*- Caudal part of intercondyloid fossa. 14- Tibial tuberosity. 15- Extensor groove. 16- Popliteal notch. 17- Lateral meniscus. 18- Medial meniscus.19- Medial articular surface. 20- Lateral articular surface. 21- Ridge. 22- Apex. 23- Base.

circular in shape. In the donkey, the medial condyle was larger than the lateral one, while in the goat ( $\mathbf{F i g . 2 B / 1 1 )}$ and in the dog ( $\mathbf{- F i g} . \mathbf{3 B} / \mathbf{1 1}$ ), the lateral condyle was larger than the medial one. Furthermore, the correlation between the length and weight of the medial and lateral condyle of the tibia was demonstrated in - Fig. $\mathbf{5}$.

The two condyles were separated by an intercondylar eminence that divided the intercondylar area into a medial and a lateral part. The medial intercondyloid eminence was more elevated than the lateral one in the donkey ( $\mathbf{F i g . 1 B / 1 2 )}$

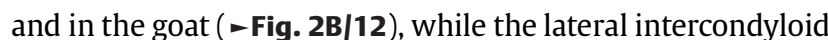
eminence ( - Fig. $\mathbf{3 B} / \mathbf{1 2}^{*}$ ) was higher than the medial one in the $\operatorname{dog}(-$ Fig. $\mathbf{3 B} / \mathbf{1 2}$ ). In the three species, there was a fossa (-Fig. 1B, 2B and 3B/13 and 13*) cranial and caudal to the intercondyloid eminence named the intercondyloid fossa. The lateral condyle separated from tibial tuberosity by the extensor groove that clear in (-Fig. 1B, $\mathbf{2 B}$ and $\mathbf{3 B} / \mathbf{1 5}$ ). The two condyles of the tibia separated caudally by the popliteal notch (-Fig. 1, 2 and 3). The length and width were calculated as means and recorded in -Table 1 . 

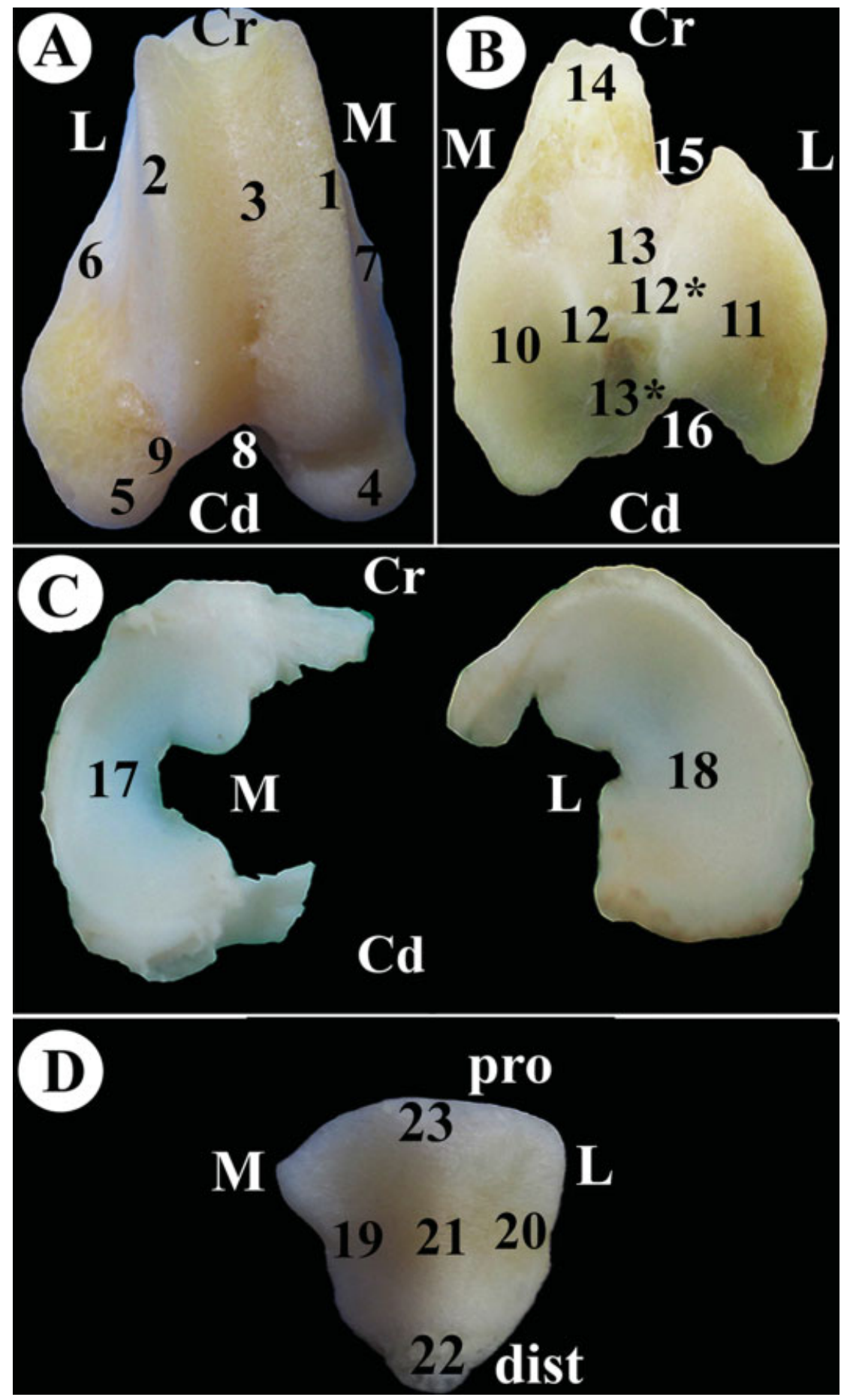

Fig. 2 Gross morphological views of the articular surfaces of the right stifle joint of the goat: (View A) clarifies the distal extremity of the femur, (View B) clarifies the proximal extremity of the tibia, (View C) clarifies the menisci, (View D) clarifies the articular surface of the patella. 1-Medial ridge of the trochlea. 2- Lateral ridge of the trochlea. 3- Groove. 4-Lateralcondyle.5- Medial condyle. 6- Lateral epicondyle. 7- Intercondyloid fossa. 8- Medial condyle. 9- Extensor fossa. 10- Medial condyle. 11- Lateral condyle. 12- Medial part of intercondyloid eminence. $12^{*}$ - Lateral part of intercondyloid eminence. 13- Cranial intercondyloid fossa. 13*- Caudal intercondyloid fossa. 14- Tibial tuberosity. 15- Extensor groove. 16- Popliteal notch. 17- Medial meniscus. 18- Lateral meniscus. 19- Medial articular surface. 20- Lateral articular surface. 21- Ridge. 22- Apex. 23- Base.

\section{Medial and Lateral Menisci (Meniscus Medialis and Lateralis)}

Generally, the medial and lateral menisci were normal, smooth, white and glistening fibrocartilage that located between the two condyles of the femur and tibia. They presented cranial and caudal poles, axial and abaxial borders and proximal and distal articular surfaces. Their proximal surface was concave to adapt to the condyles of the femur, while the distal surface was convex to the condyles of the tibia. In the donkey, the medial meniscus (-Fig. 1C/18) was crescentic in shape, while in the goat ( - Fig. 2C/18), it was semicircular, and in the dog, the medial ( - Fig. 3C/18) and lateral menisci (-Fig. 3C/19) were C-shaped. 


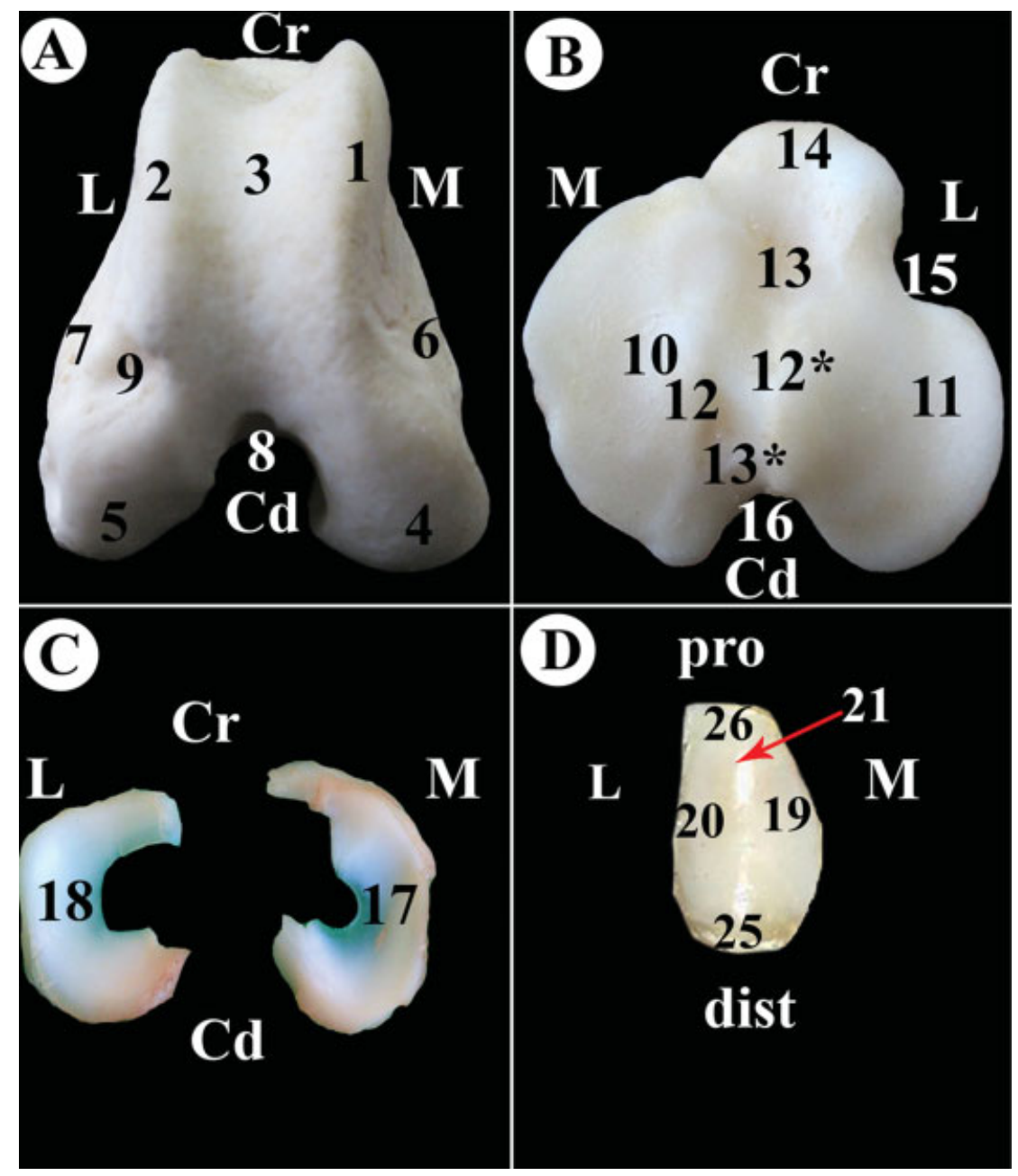

Fig. 3 Gross morphological views of the articular surfaces of the right stifle joint of the dog: (View A) clarifies the distal extremity of the right femur, (View B) clarifies the proximal extremity of the right tibia, (View C) clarifies the left menisci, (View D) clarifies the articular surface of the left patella. 1- medial ridge of the trochlea. 2- lateral ridge of the trochlea. 3- groove of the trochlea. 4- medial condyle. 5- lateral condyle. 7popliteal fossa. 8-intercondyloid fossa. 9- extensor fossa. 10-Medial condyle. 11-lateral condyle. 12-medial part of the intercondyloid eminence. $12^{*}$ - lateral part of the intercondyloid eminence. 13-cranial part of the intercondyloid fossa. 13*-caudal part of the intercondyloid fossa. 14- tibial tuberosity. 15- extensor groove. 16- popliteal notch.17-Medial meniscus. 18- lateral meniscus.19- medial articular surface. 20- lateral articular surface. 21- ridge. 22- Lateral sesamoid bone of the tendon of the gastrocnemius muscle. 23- Medial sesamoid bone of the tendon of the gastrocnemius muscle.24- sesamoid bone of the tendon of the popliteus muscle. 25- apex. 26- base.

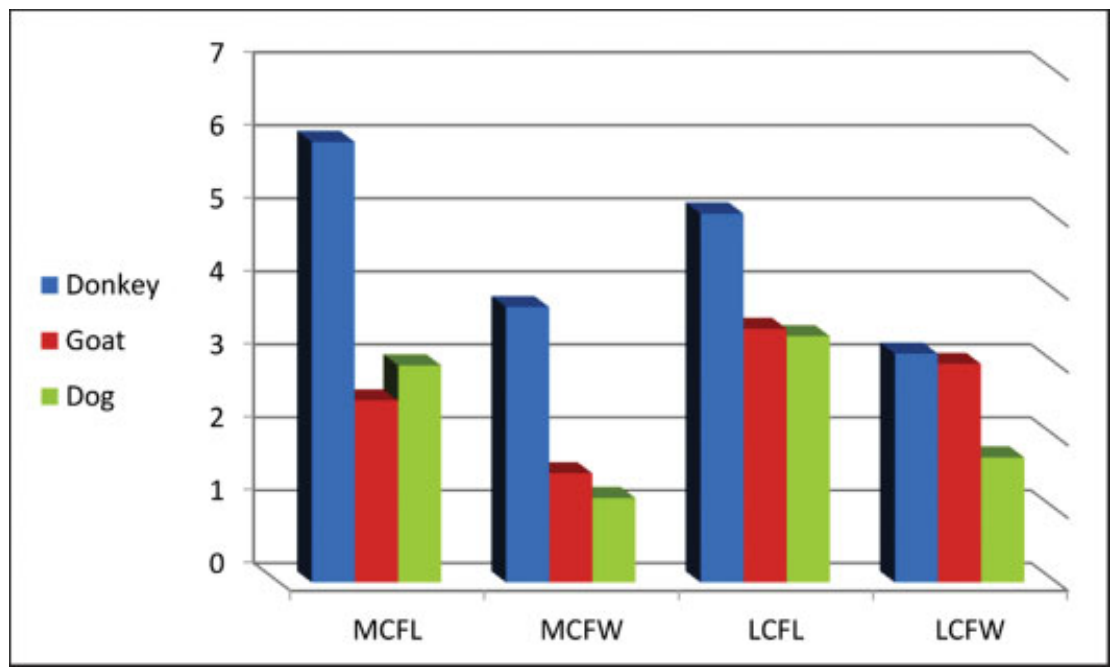

Fig. 4 Diagram to clarify the correlation between the length (MCFL) and weight (MCFW) of the medial condyle of the femur in addition to the correlation between the length (LCFL) and weight (LCFW) of the lateral condyle of the femur between the three examined animals: donkey (blue), goat (red) and dog (green). 


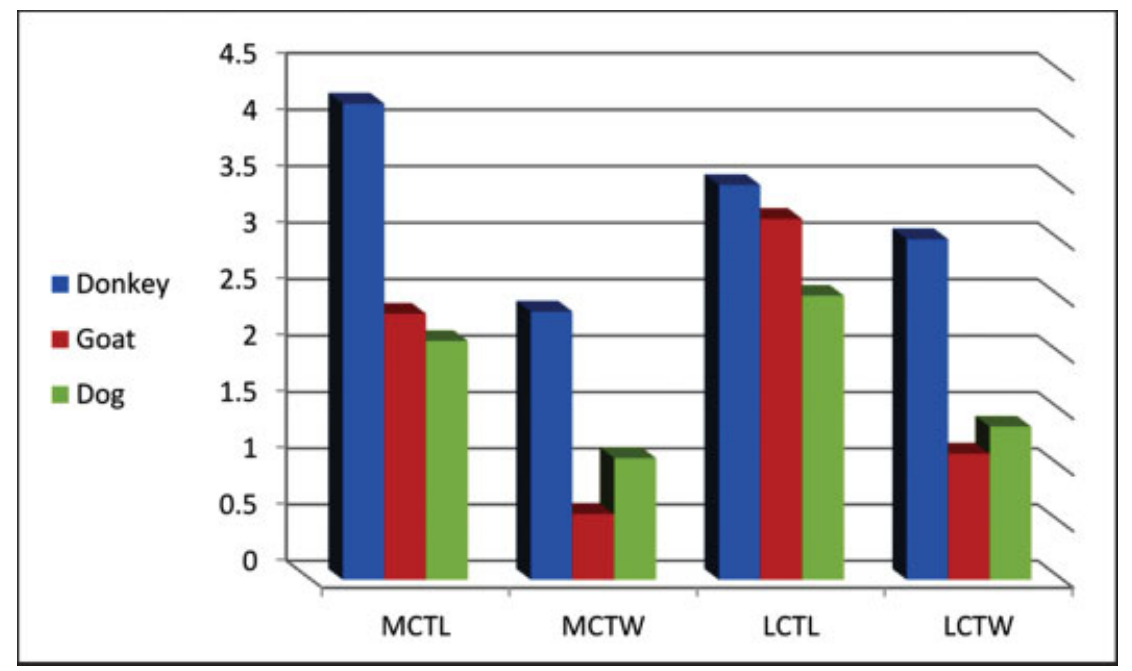

Fig. 5 Diagram to clarify the correlation between the length (MCTL) and weight (MCTW) of the medial condyle of the tibia in addition to, the correlation between the length (LCTL) and weight (LCTW) of the lateral condyle of the tibia between the three examined animals: donkey (blue), goat (red) and dog (green).
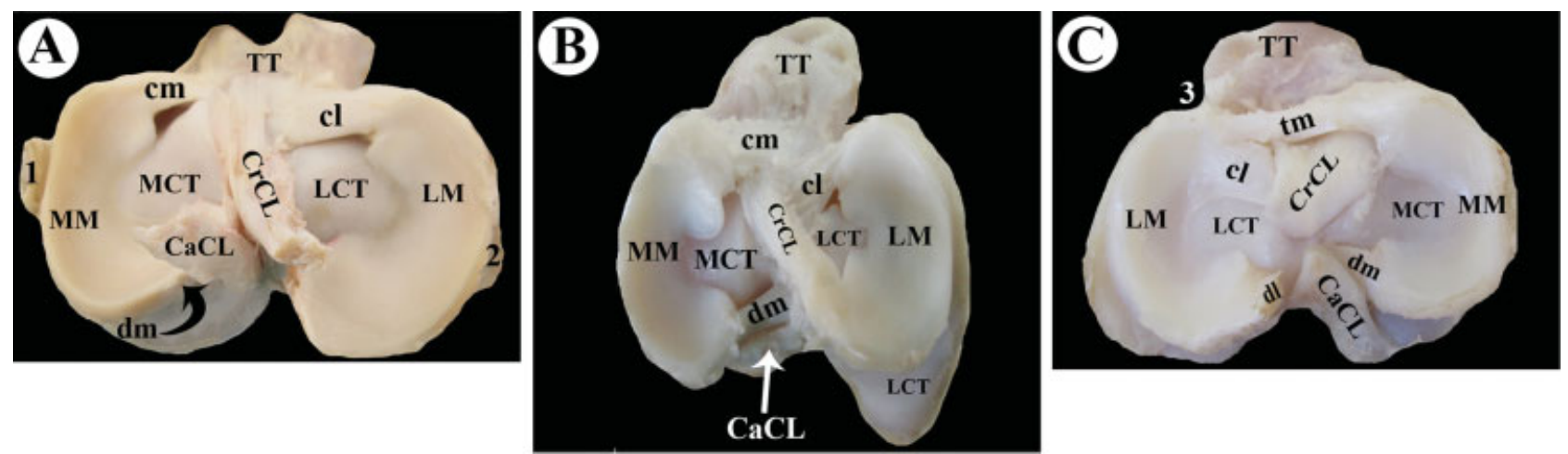

Fig. 6 Gross morphological views of the right stifle joint of the donkey (View A), right stifle joint of the goat (View B), and left stifle joint of the dog (View C) TT- tibial tuberosity. MM- medial meniscus. LM- lateral meniscus. MCT- medial condyle of the tibia. LCT- lateral condyle of the tibia. MFL- meniscofemoral ligament. $\mathrm{CrCL}$ - cranial cruciate ligament. $\mathrm{CaCL}$ - caudal cruciate ligament. $\mathrm{cm}$ - cranial ligament of the medial meniscus. cl- cranial ligament of the lateral meniscus. dm- caudal ligament of the medial meniscus. dl-caudal ligament of the lateral meniscus. tm- transverse meniscal ligament. 1- stump of the medial collateral ligament. 2. stump of the lateral collateral ligament. 3. Extensor groove.
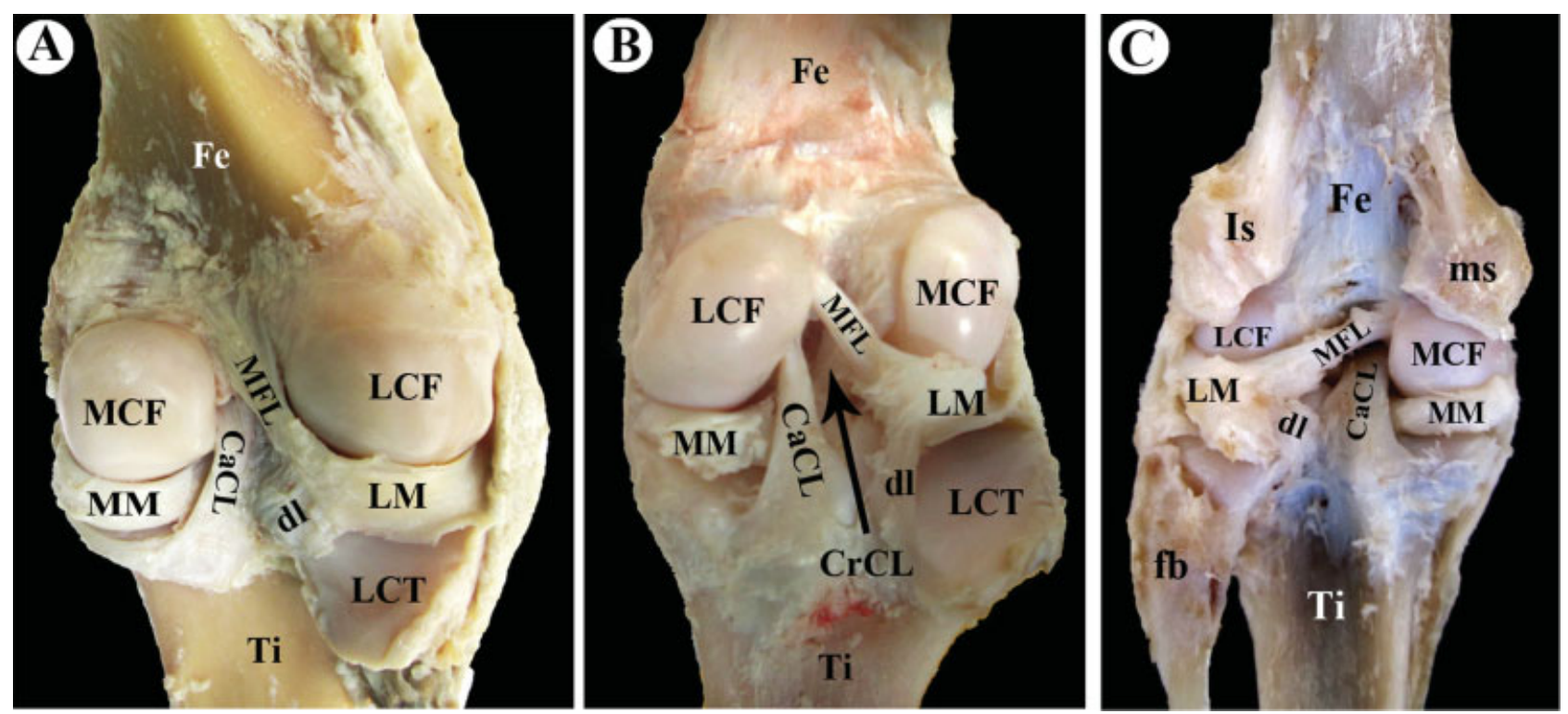

Fig. 7 Gross morphological views of the caudal view of the; right stifle joint of the donkey (View A), right stifle joint of the goat (View B), and left stifle joint of the $\operatorname{dog}($ View C) Fe-femur. Ti-tibia. MM-medial meniscus. LM-lateral meniscus. MCF-medial condyle of the femur. LCF-lateral condyle of the femur. LCT- lateral condyle of the tibia. MFL-meniscofemoral ligament. CrCL-cranial cruciate ligament. CaCl-caudal cruciate ligament. dl-caudal ligament of the lateral meniscus. 


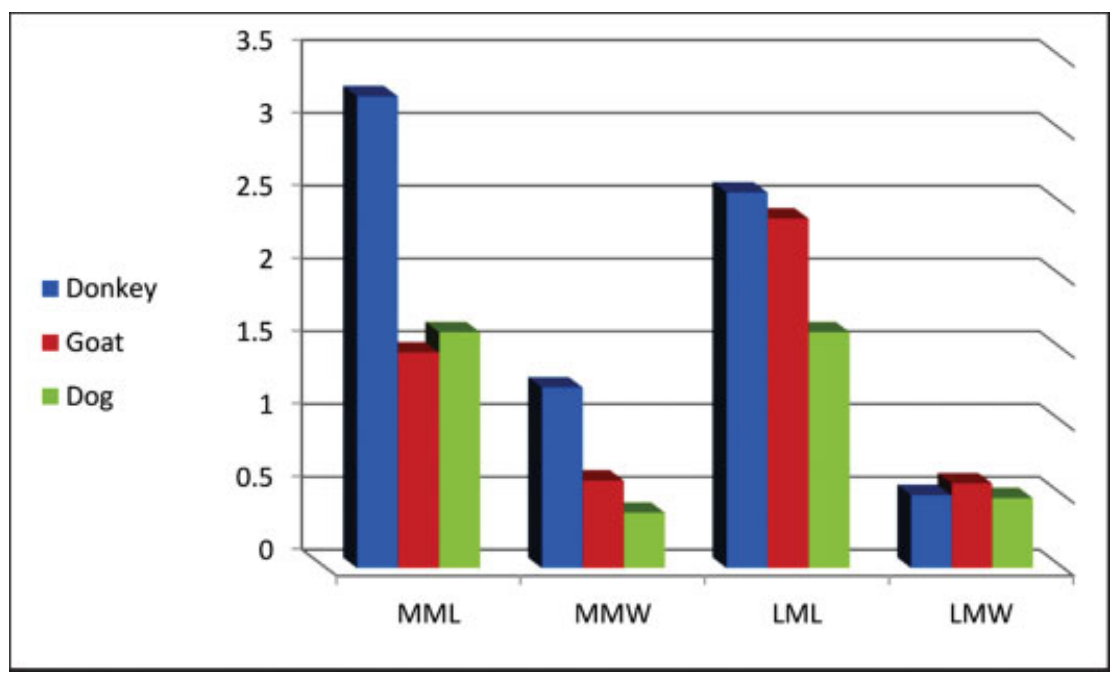

Fig. 8 Diagram to clarify the correlation between the length (MML) and weight (MMW) of the medial meniscus in addition to the correlation between the length (LML) and weight (LMW) of the lateral meniscus between the three examined animals: donkey (blue), goat (red) and dog (green).
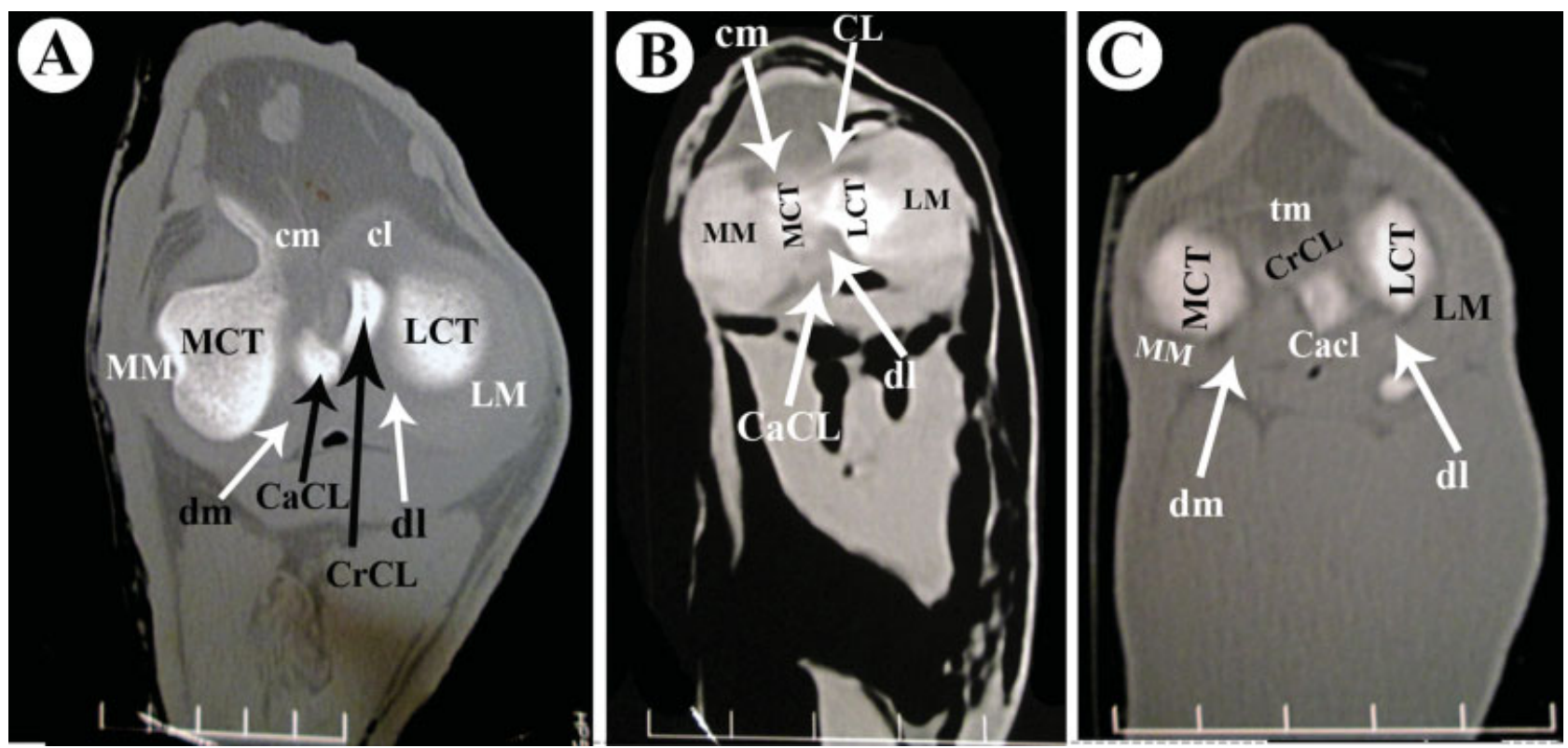

Fig. 9 Transverse computed tomography images of the right stifle joint of the donkey (view A), left stifle joint of the goat (View B), and left stifle joint of the $\operatorname{dog}(V i e w C)$ TT- tibial tuberosity. MM- medial meniscus. LM- lateral meniscus. MCT- medial condyle of the tibia. LCT- lateral condyle of the tibia. MFL- meniscofemoral ligament. CrCL-cranial cruciate ligament. CaCL- caudal cruciate ligament. cm- cranial ligament of the medial meniscus. cl-cranial ligament of the lateral meniscus. dm- caudal ligament of the medial meniscus. dl- caudal ligament of the lateral meniscus. tm- transverse meniscal ligament. 1- stump of the medial collateral ligament. 2. stump of the lateral collateral ligament. 3. Extensor groove.

In the donkey, the medial meniscus was larger than the lateral one, but in the goat and in the dog, the lateral one was the largest, and more concave and thicker. In the three species, the central border of the medial meniscus was deeper than that of the lateral one, and the peripheral border was thicker and more convex than the lateral one.

The lateral meniscus was semicircular in shape in the donkey ( $\mathbf{F i g} . \mathbf{1 C} / \mathbf{1 9}$ ), but it was shaped like and elongated kidney in the goat (-Fig. $\mathbf{2 C / 1 9}$ ). In the three examined species, the medial meniscus was firmly attached to the joint capsule while the lateral one was not. In the goat and in the dog, the central border of the two menisci was thin, concave and notched centrally. The length and width were calculated as means and recorded in - Table 1 . Furthermore, the correlation between the length and weight of the medial and lateral stifle menisci was demonstrated in - Fig. 8 .

The correlation between the body weight and dimensions of the articular surfaces of the stifle joint of the donkey, the goat and the dog are recorded in -Tables 2, $\mathbf{3}$ and $\mathbf{4}$.

\section{Meniscal Ligaments}

They included the cranial and caudal ligaments of the medial and lateral menisci, and the meniscofemoral ligament of the lateral meniscus. The cranial ligament of the medial meniscus connected the cranial pole of the medial meniscus with the cranial intercondyloid fossa of the tibia, and it measured 


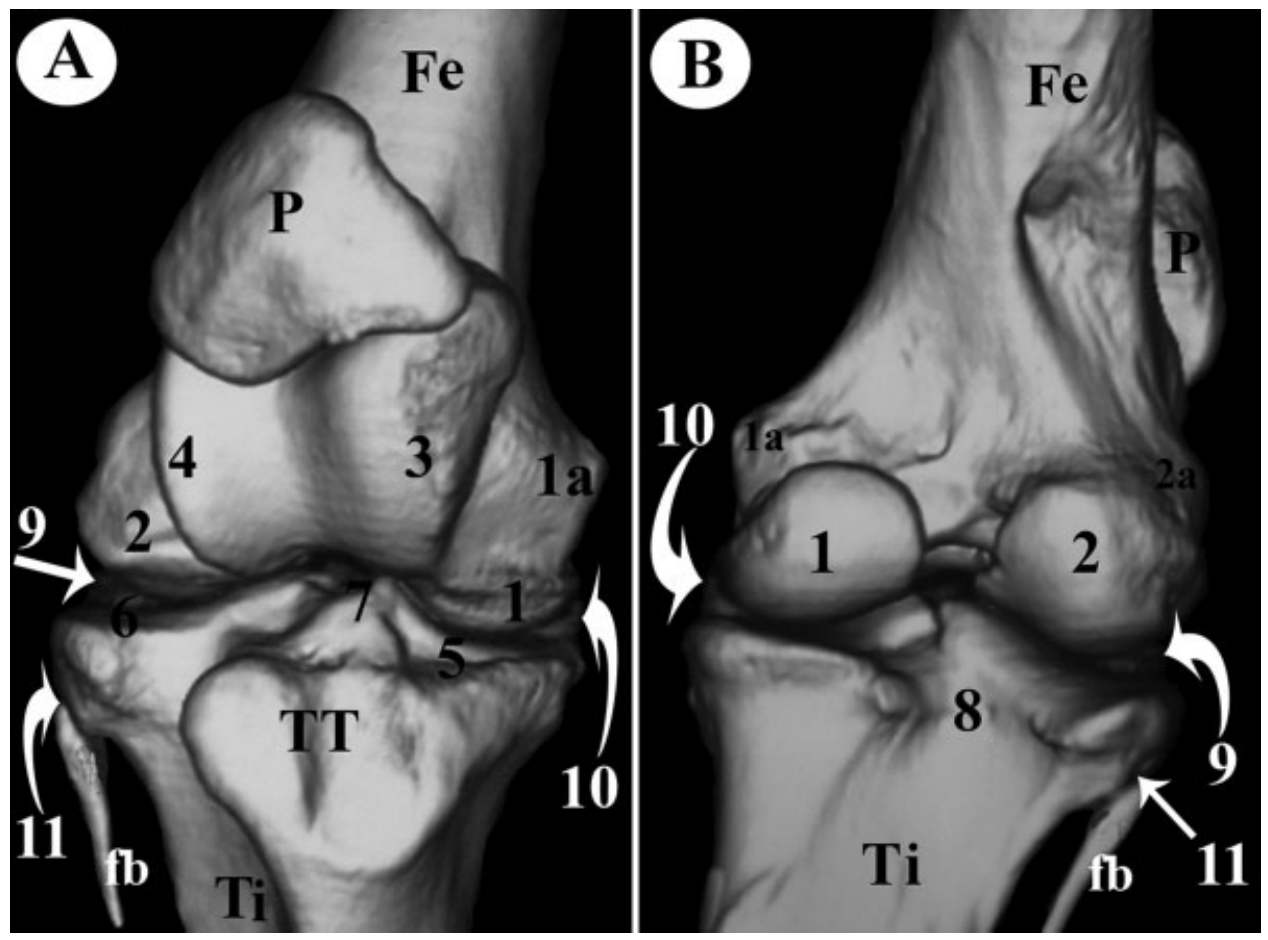

Fig. 10 Volume-rendered images (reconstruction) of the right stifle joint of the donkey: (View A) cranial and (View B) caudal views. F- femur. T-Tibia. P- patella. fb- fibula. TT- tibial tuberosity. EF- extensor fossa. 1-Medial condyle of the femur. 1a-Medial epicondyle. 2- Lateral condyle of the femur. 2a- lateral epicondyle. 3-Medial ridge of the trochlea of the femur. 4- Lateral ridge of the trochlea of the femur. 5-Medial condyle of the tibia. 6- Lateral condyle of the tibia. 7- Intercondyloid eminence. 8- Popliteal notch. 9- Extensor groove. 10- Proximal tibiofibular joint.
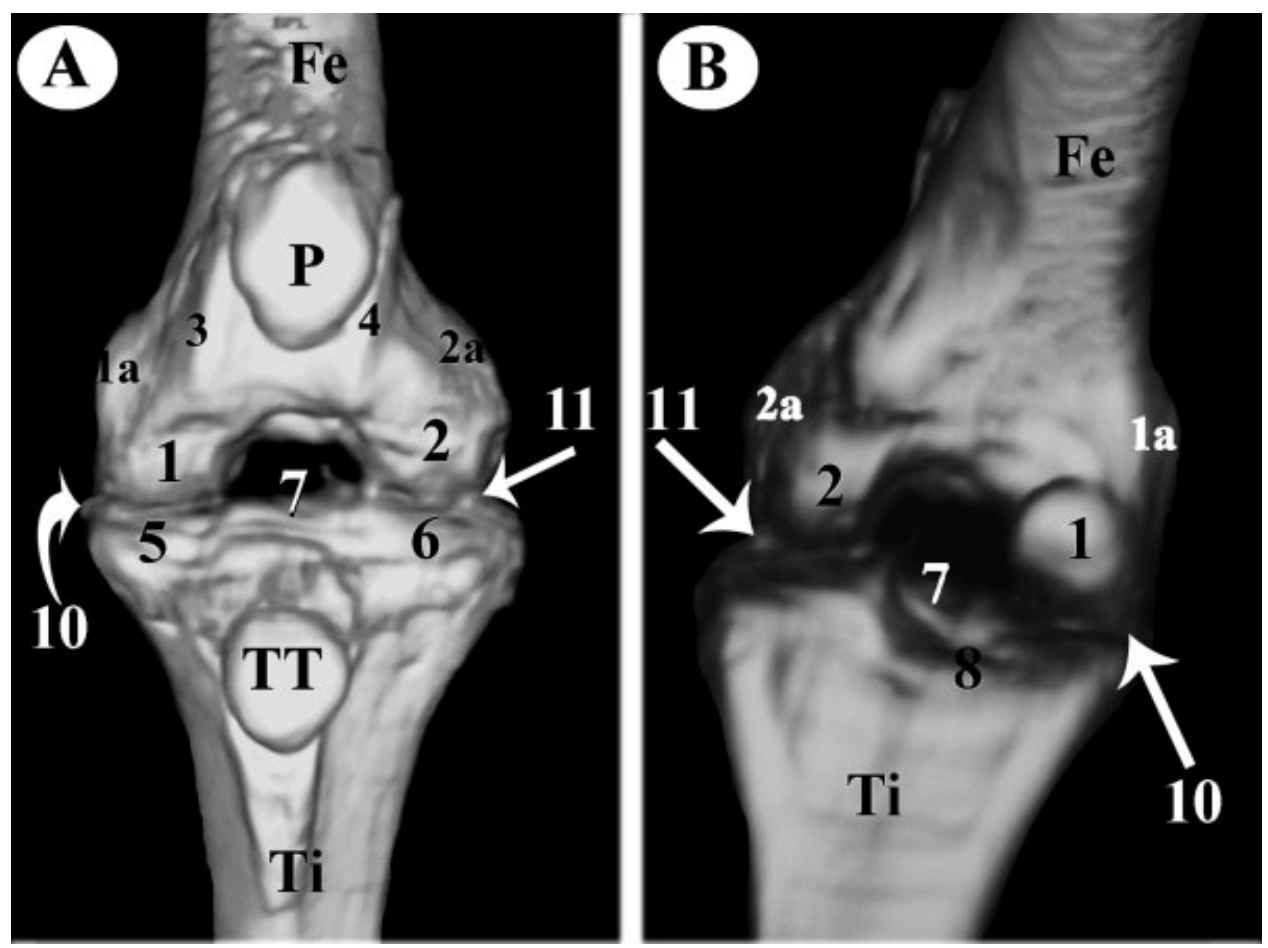

Fig. 11 Volume-rendered images (reconstruction) of the left stifle joint of the goat: (View A) cranial and (View B) caudal views. F-femur. T- tibia. P- patella. fb- fibula. TT- tibial tuberosity. 1- Medial condyle of the femur. 1a- Medial epicondyle. 2- Lateral condyle of the femur. 2a- Lateral epicondyle. 3- Medial ridge of the trochlea of the femur. 4- Lateral ridge of the trochlea of the femur. 5- Medial condyle of the tibia. 6- Lateral condyle of the tibia. 7- Intercondyloid eminence. 8- Popliteal notch. 9- Extensor groove. 10- Lateral meniscus. 

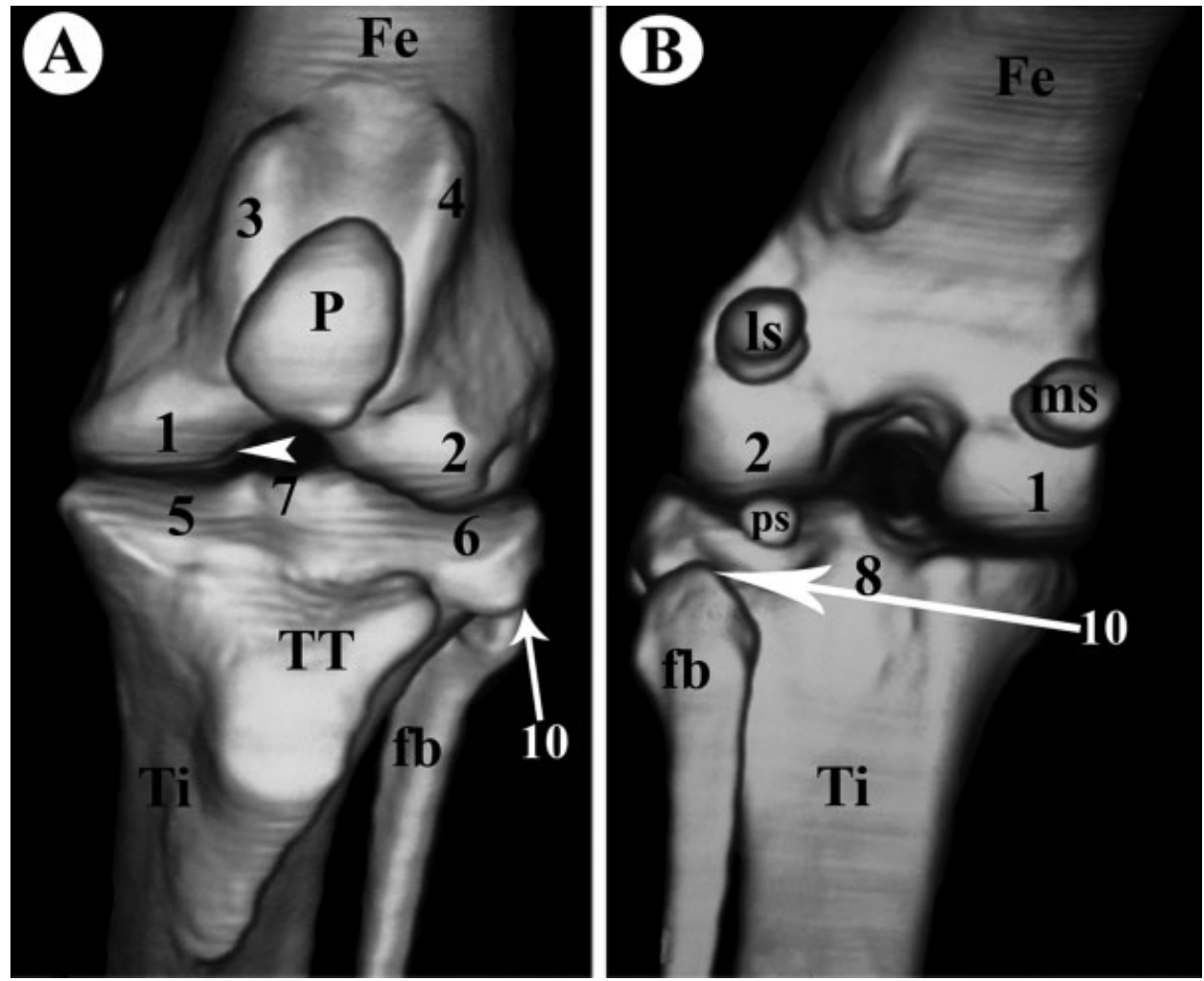

Fig. 12 Volume-rendered images (reconstruction) of the left stifle joint of the dog: (View A) cranial and (View B) caudal views. F- femur. T- tibia. P- patella. fb-fibula.TT-Tibial tuberosity. ms- medial sesamoid bone of the tendon of the gastrocnemius muscle. Is- Lateral sesamoid bone of the tendon of the gastrocnemius muscle. ps- Sesamoid bone of the tendon of the popliteus muscle. EF- extensor fossa. 1- Medial condyle of the femur. 2-Lateral condyle of the femur. 3-Medial ridge of the trochlea of the femur. 4- Lateral ridge of the trochlea of the femur. 5-Medial condyle of the tibia. 6- Lateral condyle of the tibia. 7- Intercondyloid eminence. 8- Popliteal notch. 9- Extensor groove. 10- Proximal tibiofibular joint.

Table 1 Average measurements of length (L) and weight (W) of the medial and lateral condyles of the femur and tibia in addition to the lateral and medial meniscus

\begin{tabular}{|l|l|l|l|l|l|l|}
\hline \multicolumn{2}{l}{ Item } & \multicolumn{2}{l}{ Donkey } & \multicolumn{2}{l|}{ Goat } & \multicolumn{2}{l|}{ Dog } \\
\hline \multirow{3}{*}{ Medial femoral condyle } & $\mathrm{L}$ & $6 \pm 0.3$ & $\mathrm{~L}$ & $2.5 \pm 0.31$ & $\mathrm{~L}$ & $3 \pm 0.29$ \\
\cline { 2 - 7 } & $\mathrm{W}$ & $4 \pm 0.5$ & $\mathrm{~W}$ & $1.5 \pm 0.29$ & $\mathrm{~W}$ & $1.2 \pm 0.2$ \\
\hline \multirow{3}{*}{ Lateral femoral condyle } & $\mathrm{L}$ & $5 \pm 0.35$ & $\mathrm{~L}$ & $3 \pm 0.31$ & $\mathrm{~L}$ & $3.5 \pm 0.21$ \\
\cline { 2 - 7 } & $\mathrm{W}$ & $3 \pm 0.48$ & $\mathrm{~W}$ & $3 \pm 0.2$ & $\mathrm{~W}$ & $1.6 \pm 0.21$ \\
\hline \multirow{3}{*}{ Medial tibial condyle } & $\mathrm{L}$ & $4.5 \pm 0.35$ & $\mathrm{~L}$ & $2.6 \pm 0.22$ & $\mathrm{~L}$ & $2 \pm 0.23$ \\
\cline { 2 - 7 } & $\mathrm{W}$ & $2.6 \pm 0.25$ & $\mathrm{~W}$ & $0.8 \pm 0.25$ & $\mathrm{~W}$ & $1.2 \pm 0.3$ \\
\hline \multirow{3}{*}{ Lateral tibial condyle } & $\mathrm{L}$ & $3.5 \pm 0.19$ & $\mathrm{~L}$ & $3.3 \pm 0.21$ & $\mathrm{~L}$ & $2.9 \pm 0.25$ \\
\cline { 2 - 7 } & $\mathrm{W}$ & $3.2 \pm 0.25$ & $\mathrm{~W}$ & $1 \pm 0.3$ & $\mathrm{~W}$ & $1.3 \pm 0.24$ \\
\hline \multirow{3}{*}{ Medial meniscus } & $\mathrm{L}$ & $4 \pm 0.5$ & $\mathrm{~L}$ & $1.4 \pm 0.34$ & $\mathrm{~L}$ & $1.5 \pm 0.4$ \\
\cline { 2 - 7 } & $\mathrm{W}$ & $1.2 \pm 0.2$ & $\mathrm{~W}$ & $0.8 \pm 0.35$ & $\mathrm{~W}$ & $0.6 \pm 0.34$ \\
\hline \multirow{2}{*}{ Lateral meniscus } & $\mathrm{L}$ & $2.5 \pm 0.21$ & $\mathrm{~L}$ & $2.4 \pm 0.21$ & $\mathrm{~L}$ & $1.5 \pm 0.2$ \\
\cline { 2 - 7 } & $\mathrm{W}$ & $0.6 \pm 0.19$ & $\mathrm{~W}$ & $0.5 \pm 0.19$ & $\mathrm{~W}$ & $0.5 \pm 0.24$ \\
\hline
\end{tabular}

$\sim 1.3 \mathrm{~cm}$ long and $0.7 \mathrm{~cm}$ wide in the donkey (-Fig. 6A and $\mathbf{9 A} / \mathbf{c m})$. In the goat, is measured $\sim 1.8 \mathrm{~cm}$ in length and $0.8 \mathrm{~cm}$ in width ( $\mathbf{F i g .} \mathbf{6 B}$ and $\mathbf{9 B} / \mathbf{c m}$ ). In the dog, the cranial ligament of the medial meniscus was absent, and the medial meniscus had no bony attachment to the tibia, but it was attached to the transverse or intermeniscal ligament that connected the cranial horn of the medial meniscus with the cranial ligament of the lateral meniscus, and it was located immediately cranial to the cranial ligament of the lateral meniscus, and the tibial attachment of the cranial cruciate ligament. It was $\sim 1.4 \mathrm{~cm}$ long and $0.2 \mathrm{~cm}$ wide (-Fig. $\mathbf{6 C}$ and $\mathbf{9 C} \mid \mathbf{t m}$ ).

The caudal ligament of the medial meniscus attached the caudal pole of the medial meniscus with the caudal 
Table 2 Correlation between the body weight and dimensions of the articular surfaces of the stifle joint of the donkey

\begin{tabular}{|c|c|c|c|c|c|c|c|c|}
\hline & $\begin{array}{l}\text { BW } \\
\text { Vs MCFL }\end{array}$ & $\begin{array}{l}\text { BW } \\
\text { Vs MCFW }\end{array}$ & $\begin{array}{l}\text { BW } \\
\text { Vs LCFL }\end{array}$ & $\begin{array}{l}\text { BW } \\
\text { Vs LCFW }\end{array}$ & $\begin{array}{l}\text { BW } \\
\text { Vs MCTL }\end{array}$ & $\begin{array}{l}\text { BW } \\
\text { Vs MCTW }\end{array}$ & $\begin{array}{l}\text { BW } \\
\text { Vs LCTL }\end{array}$ & $\begin{array}{l}\text { BW } \\
\text { Vs LCTW }\end{array}$ \\
\hline \multirow[t]{2}{*}{ Correlation } & 0.535 & 0.076 & .561 & 0.165 & .425 & .625 & 0.633 & 0.412 \\
\hline & $\begin{array}{l}\text { BW } \\
\text { Vs MML }\end{array}$ & $\begin{array}{l}\text { BW } \\
\text { Vs } \\
\text { MMW }\end{array}$ & $\begin{array}{l}\text { BW } \\
\text { Vs } \\
\text { LML }\end{array}$ & $\begin{array}{l}\text { BW } \\
\text { Vs } \\
\text { LMW }\end{array}$ & & & & \\
\hline Correlation & 0.798 & -0.710 & 0.472 & 0.374 & & & & \\
\hline
\end{tabular}

There is positive correlation between body weight and MCFL, MCFW, LCFL, LCFW, MCTL, MCTW, LCTL, LCTW, MML, LML, LMW, and negative correlation with MMW.

Abbreviations: LCFL, length of the lateral femoral condyle; LCFW, Width of the lateral femoral condyle; LCTL, length of the lateral tibial condyle; LCTW, width of the lateral tibial condyle; LML, length of the lateral meniscus; LMW, width of the lateral meniscus; MCFL, length of the medial femoral condyle; MCFW, width of the medial femoral condyle; MCTL, length of the medial tibial condyle; MCTW, width of the medial tibial condyle; MML, length of the medial meniscus; MMW, width of the medial meniscus.

intercondyloid fossa of the tibia. In the donkey, it measured $\sim 1 \mathrm{~cm}$ in length and width ( - Fig. $\mathbf{6 A} / \mathbf{d m}$ ), while it was $\sim 0.5 \mathrm{~cm}$ in length and $0.3 \mathrm{~cm}$ in width in the goat (-Fig. 6B and $\mathbf{9 B} / \mathbf{d m}$ ). In the $\operatorname{dog}(\mathbf{- F i g . 6 C}$ and $\mathbf{9 C} / \mathbf{d m}$ ), it attached cranial to the tibial attachment of the caudal cruciate ligament and it was $\sim 0.2 \mathrm{~cm}$ in length and $0.1 \mathrm{~cm}$ in width.

The cranial ligament of the lateral meniscus connected the cranial pole of the lateral meniscus with the cranial intercondyloid fossa of the tibia. It was longer and thicker than that of the medial meniscus in the donkey (-Fig. $\mathbf{6 A}$ and $\mathbf{9 A / c l}$ ), it measured $\sim 1.5 \mathrm{~cm}$ long and $1.3 \mathrm{~cm}$ wide. In the goat, it was $\sim 0.7 \mathrm{~cm}$ in length and width ( - Fig. $\mathbf{6 B}$ and $\mathbf{9 B} / \mathbf{c l}$ ), while in the dog, it was $\sim 0.3 \mathrm{~cm}$ in length and $0.1 \mathrm{~cm}$ in width( - Fig. $\mathbf{6 C} / \mathbf{c l})$. In the dog, the cranial ligament of the lateral meniscus was located caudal to the transverse ligament, the caudal one was longer than the caudal ligament of the medial meniscus. The caudal ligament of the lateral meniscus connected the caudal pole of the lateral meniscus and divided into two parts, one attached to the medial part of the medial condyle of the tibia and the other to the popliteal notch. It measured $\sim 1.5 \mathrm{~cm}$ long and $0.9 \mathrm{~cm}$ wide in the donkey ( $\mathbf{F i g . 5 A}$ and $\mathbf{9 A} / \mathbf{d I}$ ). In the goat, it measured $0.5 \mathrm{~cm}$ in length and $0.2 \mathrm{~cm}$ in width ( $\mathbf{- F i g . ~ 7 B}$ and $\mathbf{9 B} / \mathbf{d I}$ ), while in the dog, it was $\sim 0.3 \mathrm{~cm}$ long and $0.2 \mathrm{~cm}$ wide (-Fig. $7 \mathbf{C}$ and $\mathbf{9 C} / \mathbf{d l}$ ).

The meniscofemoral ligament connected the caudal pole of the lateral meniscus with the intercondyloid fossa of the femur. It measured $\sim 2.7 \mathrm{~cm}$ in length and $0.8 \mathrm{~cm}$ in width in the donkey ( - Fig. 10A/MFL); $\sim 1.5 \mathrm{~cm}$ in length and $0.5 \mathrm{~cm}$ in width in the goat ( - Fig. 10B/MFL), and $\sim 1.3 \mathrm{~cm}$ long and $0.4 \mathrm{~cm}$ wide in the $\operatorname{dog}$ ( - Fig. $\mathbf{1 0 C} / \mathbf{M F L}$ ). The length and width were calculated as means and recorded in - Table $\mathbf{5}$.

The correlation between the body weight and dimensions of the articular surfaces of the stifle joint of the donkey, the goat and the dog are recorded in -Table 2, 3 and $\mathbf{4}$.

With volume-rendering reconstruction techniques, 3DCT (-Fig. 10, 11 and 12) images were produced, rotated and sectioned as desired. In 3D images (reconstruction), the characteristic features of the articular surfaces of the joint of each species evaluated (donkeys, goats and dogs), in which the lateral condyle of the femur appeared larger in the goat and in the dog.

\section{Discussion}

The present study was performed to describe the morphological features of the stifle menisci of donkeys, goats and dogs using gross anatomy, and CT, with special references to the articular surfaces. The animals have been chosen on the basis of the donkey being of the equine species, which is knows for carrying heavy loads for long distances; the goat being of the ruminant species, known for its limited mobility, and the dog of the carnivores that characterized by its fastmoving.

Table 3 Correlation between the body weight and dimensions of the articular surfaces of the stifle joint of the goat

\begin{tabular}{|l|l|l|l|l|l|l|l|l|}
\hline & $\begin{array}{l}\text { BW } \\
\text { Vs MCFL }\end{array}$ & $\begin{array}{l}\text { BW } \\
\text { Vs MCFW }\end{array}$ & $\begin{array}{l}\text { BW } \\
\text { Vs LCFL }\end{array}$ & $\begin{array}{l}\text { BW } \\
\text { Vs LCFW }\end{array}$ & $\begin{array}{l}\text { BW } \\
\text { Vs MCTL }\end{array}$ & $\begin{array}{l}\text { BW } \\
\text { Vs MCTW }\end{array}$ & $\begin{array}{l}\text { BW } \\
\text { Vs LCTL }\end{array}$ & $\begin{array}{l}\text { BW } \\
\text { Vs } \\
\text { LCTW }\end{array}$ \\
\hline Correlation & 0.226 & 0.042 & .325 & 0.510 & 0.082 & -0.075 & 0.246 \\
\hline & BW & $\begin{array}{l}\text { BW } \\
\text { Vs } \\
\text { MML }\end{array}$ & $\begin{array}{l}\text { BW } \\
\text { Vs LML }\end{array}$ & $\begin{array}{l}\text { BW } \\
\text { Vs } \\
\text { LMW }\end{array}$ & & & & \\
& MMW & 0.283 & 0.356 & 0.439 & & & \\
\hline Correlation & 0.344 & 0.0742 & \\
\hline
\end{tabular}

There is positive correlation between body weight and MCFL, MCFW, LCFL, LCFW, MCTL, LCTL, LCTW, MML, LML, LMW, and negative correlation with MCTW. Abbreviations: LCFL, length of the lateral femoral condyle; LCFW, width of the lateral femoral condyle; LCTL, length of the lateral tibial condyle; LCTW, width of the lateral tibial condyle; LML, length of the lateral meniscus; LMW, width of the lateral meniscus; MCFL, length of the medial femoral condyle; MCFW, width of the medial femoral condyle; MCTL, length of the medial tibial condyle; MCTW, width of the medial tibial condyle; MML, length of the medial meniscus; MMW, width of the medial meniscus. 
82 Stifle Menisci of Donkeys, Goats and Dogs Abumandour et al.

Table 4 Correlation between the body weight and dimensions of the articular surfaces of the stifle joint of the dog

\begin{tabular}{|l|l|l|l|l|l|l|l|l|}
\hline & $\begin{array}{l}\text { BW } \\
\text { Vs } \\
\text { MCFL }\end{array}$ & $\begin{array}{l}\text { BW } \\
\text { Vs } \\
\text { MCFW }\end{array}$ & $\begin{array}{l}\text { BW } \\
\text { Vs } \\
\text { LCFL }\end{array}$ & $\begin{array}{l}\text { BW } \\
\text { Vs } \\
\text { LCFW }\end{array}$ & $\begin{array}{l}\text { BW } \\
\text { Vs MCTL }\end{array}$ & $\begin{array}{l}\text { BW } \\
\text { Vs MCTW }\end{array}$ & $\begin{array}{l}\text { BW } \\
\text { Vs } \\
\text { LCTL }\end{array}$ & $\begin{array}{l}\text { BW } \\
\text { Vs } \\
\text { LCTW }\end{array}$ \\
\hline Correlation & 0.247 & 0.403 & 0.449 & 0.054 & 0.037 & 0.165 & 0.322 \\
\hline & BW & $\begin{array}{l}\text { BW } \\
\text { Vs } \\
\text { MML }\end{array}$ & $\begin{array}{l}\text { BW } \\
\text { Vs } \\
\text { MMW }\end{array}$ & $\begin{array}{l}\text { BW } \\
\text { Vs } \\
\text { LMW }\end{array}$ & & & & 0.453 \\
\hline Correlation & 0.559 & 0.505 & 0.559 & 0.291 & & & \\
\end{tabular}

There is a positive correlation between body weight and MCFL, MCFW, LCFL, LCFW, MCTL, MCTW, LCTL, LCTW, MML, LML, LMW.

Abbreviations: LCFL, length of the lateral femoral condyle; LCFW, width of the lateral femoral condyle; LCTL, length of the lateral condyle of the tibia; LCTW, width of the lateral condyle of the tibia; LML, length of the lateral meniscus; LMW, width of the lateral meniscus; MCFL, length of the medial femoral condyle; MCFW, width of the medial femoral condyle; MCTL, length of the medial condyle of the tibia; MCTW, width of the medial condyle of the tibia; MML, length of the medial meniscus; MMW, width of the medial meniscus.

Table 5 Average measurements of length (L) and weight (W) of the meniscal ligament of the stifle joint

\begin{tabular}{|c|c|c|c|c|c|c|}
\hline & \multicolumn{2}{|c|}{ Donkey } & \multicolumn{2}{|c|}{ Goat } & \multirow{2}{*}{\multicolumn{2}{|c|}{$\frac{\text { Dog }}{\text { Absent }}$}} \\
\hline \multirow[t]{2}{*}{ Cranial ligament of the medial meniscus } & $\mathrm{L}$ & $1.3 \mathrm{~cm}$ & $\mathrm{~L}$ & $0.5 \mathrm{~cm}$ & & \\
\hline & W & $0.7 \mathrm{~cm}$ & W & $1.8 \mathrm{~cm}$ & & \\
\hline \multirow[t]{2}{*}{ Transverse ligament } & \multirow{2}{*}{\multicolumn{2}{|c|}{ Absent }} & \multirow{2}{*}{\multicolumn{2}{|c|}{ Absent }} & $\mathrm{L}$ & $1.4 \mathrm{~cm}$ \\
\hline & & & & & W & $0.2 \mathrm{~cm}$ \\
\hline \multirow[t]{2}{*}{ Caudal ligament of medial meniscus } & L & $1 \mathrm{~cm}$ & L & $0.5 \mathrm{~cm}$ & $\mathrm{~L}$ & $0.2 \mathrm{~cm}$ \\
\hline & W & $1 \mathrm{~cm}$ & W & $0.3 \mathrm{~cm}$ & W & $0.1 \mathrm{~cm}$ \\
\hline \multirow[t]{2}{*}{ Cranial ligament of lateral meniscus } & $\mathrm{L}$ & $1.5 \mathrm{~cm}$ & $\mathrm{~L}$ & $0.7 \mathrm{~cm}$ & $\mathrm{~L}$ & $0.3 \mathrm{~cm}$ \\
\hline & W & $1.3 \mathrm{~cm}$ & W & $0.7 \mathrm{~cm}$ & W & $0.1 \mathrm{~cm}$ \\
\hline \multirow[t]{2}{*}{ Caudal ligament of lateral meniscus } & $\mathrm{L}$ & $1.5 \mathrm{~cm}$ & $\mathrm{~L}$ & $0.5 \mathrm{~cm}$ & $\mathrm{~L}$ & $0.3 \mathrm{~cm}$ \\
\hline & W & $0.9 \mathrm{~cm}$ & W & $0.2 \mathrm{~cm}$ & W & $0.2 \mathrm{~cm}$ \\
\hline \multirow[t]{2}{*}{ Meniscofemoral ligament } & L & $2.7 \mathrm{~cm}$ & L & $1.5 \mathrm{~cm}$ & $\mathrm{~L}$ & $1.3 \mathrm{~cm}$ \\
\hline & W & $0.8 \mathrm{~cm}$ & W & $0.5 \mathrm{~cm}$ & W & $0.4 \mathrm{~cm}$ \\
\hline
\end{tabular}

Concerning the articular surfaces of the femorotibial joint, they were the condyles of the femur and tibia and the menisci. The medial condyle of the femur of the donkey, goat and dog was oblique in direction and smaller than the lateral in the donkey and goat, this was observed by ${ }^{25}$ in the donkey and mule and like that of the horse ${ }^{26}$ and camel ${ }^{27}$ while, the lateral condyle was sagittal in direction, this agreed with that observed by ${ }^{25}$ in the donkey and mule, ${ }^{26}$ in the horse and ${ }^{28}$ in the dog.

The current investigation mentioned that the medial condyle of the femur was larger than the lateral one in the donkey, while it was smaller and lower than the lateral one in the goat and in the dog. The results in the dog and in the goat are similar to those obtained by ${ }^{29}$ in the marsh deer and ${ }^{9,30}$ in the ovine.

In the dog, the articular surfaces of the two condyles were continuous proximocaudally with small articular facet for sesamoid bones, which present in the tendons of the medial and lateral head of the gastrocnemius muscle; however, this is absent in the horse and in the goat. Similar results were noted by ${ }^{9,29}$ in sheep and deer. In the dog, the femoral condyles were articulated with the sesamoid bones of the tendons of the gastrocnemius muscle, this agreed with that described by ${ }^{28}$ in the dog.
The medial condyle of the tibia was triangular in shape in the donkey and goat likes that of the donkey and mule ${ }^{25}$ and in the camel, ${ }^{27}$ while that of the dog was oval in shape and the lateral condyle was circular as noted by. ${ }^{28}$ The adaptation of the condyles of the femur and tibia was compensated by the presence of the menisci, which increase femorotibial joint stability and congruency and serve as the shock absorbers of the stifle. ${ }^{31,32}$ The medial meniscus of the donkey was crescentic in shape, as mentioned by,${ }^{25}$ while in the goat, it was semicircular, and in the dog, the medial and lateral menisci were C-shaped.

In general, the normal medial and lateral menisci were smooth, white and located between the two condyles of the femur and tibia to improve joint adaptation. ${ }^{2,4,5,9,10,33}$ In the examined donkey and goat, the meniscal ligaments included the cranial and caudal ligaments of the medial and lateral menisci and the meniscofemoral ligament of the lateral meniscus, similar to that observed by ${ }^{26,34,35}$ in horse, ${ }^{36,37}$ in ovine, ${ }^{27}$ in camel and ${ }^{4}$ in humans, sheep and rabbits. In the dog, the cranial ligament of the medial meniscus was absent, and the medial meniscus had no bony attachment to the tibia, but it was attached to the transverse intermeniscal ligament, which connected the cranial horn of the medial 
meniscus to the cranial ligament of the lateral meniscus. This did not agree with the findings of ${ }^{28}$ in the dog. Moreover, the absence of the caudal ligament of the lateral menisci was recorded in rabbits by. 4,38

In the current study, there is a transverse intermeniscal ligament that connects the cranial horn of the medial meniscus with the cranial ligament of the lateral meniscus in the dog, but the present study did not record this ligament in the donkey and the goat. The transverse intermeniscal ligament was also observed by ${ }^{33}$ in tigers, ${ }^{4,38}$ rabbits and ${ }^{39-42}$ in dogs and cats. They also ${ }^{43}$ described this ligament in the dog and pig, but reported that it was absent in sheep. The transverse intermeniscal ligament was also absent in donkey and goat, in the current study, and sheep ${ }^{9}$ and deer. ${ }^{29}$

The meniscofemoral ligament connected the caudal pole of the lateral meniscus with the intercondyloid fossa of the femur. The similar observations were recorded in all animal species $25,29,33,39,42$

\section{Conclusion}

The medial condyle of the femur was larger than the lateral one in the donkey, while it was smaller and lower than the lateral one in the goat and in the dog. In the donkey, the medial meniscus was larger than the lateral one, but in the goat and in the dog, the lateral meniscus was the largest, more concave and thicker. The meniscus ligaments included cranial and caudal ligaments of the medial and lateral menisci, and the meniscofemoral ligament of the lateral meniscus. In the dog, the cranial ligament of medial meniscus was absent, and the medial meniscus had no bony attachment to tibia, but it attached to the transverse intermeniscal ligament, which connected the cranial horn of the medial meniscus with the cranial ligament of lateral meniscus. The meniscofemoral ligament connected the caudal pole of the lateral meniscus with the intercondyloid fossa of the femur.

\section{Contribution of the Authors to the Manuscript}

All authors confirm their contribution. Mohamed Abumandour was responsible for the data collection, data analysis, manuscript writing/editing, anatomical dissection and protocol/project development. Samir El-Gendy was responsible for the protocol/project development and the manuscript revision. Ashraf Karkoura was responsible for following up the protocol/project and for the manuscript revision. Raafat El-Bakary was responsible for following up the data analysis and the manuscript preparation. Naglaa Fathi was responsible for the manuscript writing/editing, protocol/project development, data collection, data analysis and anatomical dissection.

\section{Ethics Approval and Consent to Participate}

The present article was performed with the approval of the Bioethics Committee and in accordance with the guidelines for the care and use of laboratory animals and the Animal Welfare and Ethics Committee of the Faculty of Veterinary Medicine at Alexandria University, following the Egyptian laws.
Data and Material Availability

All data used in this study were included in this published article.

Conflicts of Interest

The authors have no conflicts of interest to declare.

\section{Acknowledgment}

The authors thank Dr. Sahar El-Naggar for the help in the process of statistical analysis during this study.

\section{References}

1 Parsons FG. The joints of mammals compared with those of man: a course of lectures delivered at the Royal College of Surgeons of England. J Anat Physiol 1899;34(Pt 1):41-68

2 Messner K, Gao J. The menisci of the knee joint. Anatomical and functional characteristics, and a rationale for clinical treatment. J Anat 1998;193(Pt 2):161-178

3 McDevitt CA, Webber RJ. The ultrastructure and biochemistry of meniscal cartilage. Clin Orthop Relat Res 1990;(252):8-18

4 Chevrier A, Nelea M, Hurtig MB, Hoemann CD, Buschmann MD. Meniscus structure in human, sheep, and rabbit for animal models of meniscus repair. J Orthop Res 2009;27(09):1197-1203

5 Fithian DC, Kelly MA, Mow VC. Material properties and structurefunction relationships in the menisci. Clin Orthop Relat Res 1990; (252):19-31

6 Rath E, Richmond JC. The menisci: basic science and advances in treatment. Br J Sports Med 2000;34(04):252-257

7 Deponti D, Di Giancamillo A, Scotti C, Peretti GM, Martin I. Animal models for meniscus repair and regeneration. J Tissue Eng Regen Med 2015;9(05):512-527

8 Walmsley JP. Vertical tears of the cranial horn of the meniscus and its cranial ligament in the equine femorotibial joint: 7 cases and their treatment by arthroscopic surgery. Equine Vet J 1995;27(01): 20-25

9 Allen MJ, Houlton JE, Adams SB, Rushton N. The surgical anatomy of the stifle joint in sheep. Vet Surg 1998;27(06):596-605

10 Aspden RM, Yarker YE, Hukins DW. Collagen orientations in the meniscus of the knee joint. J Anat 1985;140(Pt 3):371-380

11 Ghadially FN, Thomas I, Yong N, Lalonde JM. Ultrastructure of rabbit semilunar cartilages. J Anat 1978;125(Pt 3):499-517

12 Ghadially FN, Wedge JH, Lalonde JM. Experimental methods of repairing injured menisci. J Bone Joint Surg Br 1986;68(01): 106-110

13 Krause WR, Pope MH, Johnson RJ, Wilder DG. Mechanical changes in the knee after meniscectomy. J Bone Joint Surg Am 1976;58 (05):599-604

14 Weaver A. Bovine medicine diseases and husbandry of cattle. In Andrews A, Blowey R, Boyd H, Eddy R, Eds. 2nd ed. Oxford: Blackwell Science Ltd.; 435-652004

15 Huangfu X, Zhao J. Tendon-bone healing enhancement using injectable tricalcium phosphate in a dog anterior cruciate ligament reconstruction model. Arthroscopy 2007;23(05):455-462

16 Meller R, Kendoff D, Hankemeier S, et al. Hindlimb growth after a transphyseal reconstruction of the anterior cruciate ligament: a study in skeletally immature sheep with wide-open physes. Am J Sports Med 2008;36(12):2437-2443

17 Spindler KP, Murray MM, Carey JL, Zurakowski D, Fleming BC. The use of platelets to affect functional healing of an anterior cruciate ligament $(\mathrm{ACL})$ autograft in a caprine ACL reconstruction model. J Orthop Res 2009;27(05):631-638

18 Murray MM, Magarian E, Zurakowski D, Fleming BC. Bone-tobone fixation enhances functional healing of the porcine anterior cruciate ligament using a collagen-platelet composite. Arthroscopy 2010;26(9, Suppl)S49-S57 
19 Badawy AM. Computed Tomographic anatomy of the fore foot in one-humped camel (Camelus dromedrus). Glob Vet 2011;6: 417-423

20 Widmer WR, Buckwalter KA, Braunstein EM, Hill MA, O'Connor BL, Visco DM. Radiographic and magnetic resonance imaging of the stifle joint in experimental osteoarthritis of dogs. Vet Radiol Ultrasound 1994;35:371-383

21 Baird DK, Hathcock JT, Rumph PF, Kincaid SA, Visco DM. Low-field magnetic resonance imaging of the canine stifle joint: normal anatomy. Vet Radiol Ultrasound 1998;39(02):87-97

22 Pretorius ES, Fishman EK. Volume-rendered three-dimensional spiral CT: musculoskeletal applications. Radiographics 1999;19 (05):1143-1160

23 Nomina AnatomicaVeterinaria (NAV). International Committee on Veterinary Gross Anatomical Nomenclature and authorized by the general assembly of the world Association of veterinary Anatomist. Knoxville, 3rd Ed. Ghent. Published by the Editorial Committee Hanover (Germany), Ghent (Belgium), Columbia, MO (U.S.A.), Rio de Janeiro (Brazil)2017

24 corporation I. IBM SPSS statistics for Windows, version 21.0. IBM Corporation Armonk eNY NY; 2012

25 El-Bakary R. Comparative anatomical and clinical studies on the stifle joint of the mule and donkey. Zagazig Veterinary Journal (Egypt) 1993

26 Getty R. The Anatomy of the Domestic Animals. Vol.1, 5th Ed. W.B. Saunders CompanyPhiladelpshia, USA1975

27 Karkoura AA. Applied Anatomical Studies On The Stifle Joint Of The One-Humped Camel (Camelus Domedrius). alex. J Vet Sci 1991;6:19-38

28 Evans HE, de Lahunta A. Miller's ANATOMY of the DOG fourth edition. W. B. Saunders CompanyPhiladelphia11812013

29 Shigue DA, Rahal SC, Schimming BC, et al. Evaluation of the marsh deer stifle joint by imaging studies and gross anatomy. Anat Histol Embryol 2015;44(06):468-474

30 Hette K, Rahal SC, Mamprim MJ. Volpi RdS, Silva VCd, Ferreira DOL. Radiographic and ultrasonographic evaluations of the ovine stifle joint. Pesqui Vet Bras 2008;28:393-398

31 Brantigan OC, Voshell AF. The mechanics of the ligaments and menisci of the knee joint. J Bone Joint Surg Am 1941;23:44-66
32 Bylski-Austrow DI, Ciarelli MJ, Kayner DC, Matthews LS, Goldstein SA. Displacements of the menisci under joint load: an in vitro study in human knees. J Biomech 1994;27(04):421-431

33 Arencibia A, Encinoso M, Jáber JR, et al. Magnetic resonance imaging study in a normal Bengal tiger (Panthera tigris) stifle joint. BMC Vet Res 2015;11:192

34 De Lahunta A, Habel RE. Applied veterinary anatomy. Library of Congress Cataloging in Publication Data. W.B. Saunders Company. Philadelphia, London, Toronto, Mexico City, Rio de Janeiro, Sydney, Tokyo, Hong Kong.1986

35 Hoegaerts M, Nicaise M, Van Bree H, Saunders JH. Cross-sectional anatomy and comparative ultrasonography of the equine medial femorotibial joint and its related structures. Equine Vet J 2005;37 (06):520-529

36 Vandeweerd JM, Kirschvink N, Muylkens B, et al. Magnetic resonance imaging (MRI) anatomy of the ovine stifle. Vet Surg 2013;42(05):551-558

37 Rosvold JM, Atarod M, Heard BJ, O'Brien EJ, Frank CB, Shrive NG. Ligament and meniscus loading in the ovine stifle joint during normal gait. Knee 2016;23(01):70-77

38 Orhan IO, Haziroglu RM, Gultiken ME. The ligaments and sesamoid bones of knee joint in New Zealand rabbits. Anat Histol Embryol 2005;34(02):65-71

39 Dyce KM, Sack WO, Wensing CJG. Text book of Veterinary anatomy. W.B. Saunders CompanyPhiladelphia, London and Toronto2010

40 Nickel R, Schummer A, Seiferle E, Frewein J, Wilkens H, Wille KH. The Locomotor System of the Domestic Mammals "Skeleton of the Head of Ruminants" 149-154. Verlag Paul PareyBerlin-Hamburg, Germany1986

41 Soler M, Murciano J, Latorre R, Belda E, Rodríguez MJ, Agut A. Ultrasonographic, computed tomographic and magnetic resonance imaging anatomy of the normal canine stifle joint. Vet J 2007;174(02):351-361

42 Gupte CM, Bull AM, Murray R, Amis AA. Comparative anatomy of the meniscofemoral ligament in humans and some domestic mammals. Anat Histol Embryol 2007;36(01):47-52

43 Barone R. Articulation fémoro-tibio-rotulienne. Anatomie Comparée des Mammifères Domestiques 1968;2:296 